\title{
Adipose tissue function in healthy pregnancy, gestational diabetes mellitus and pre-eclampsia
}

\author{
Cara Trivett $\mathbb{D}^{1} \cdot$ Zoe J. Lees $^{1} \cdot$ Dilys J. Freeman $\mathbb{D}^{1}$
}

Received: 17 September 2020 / Revised: 30 April 2021 / Accepted: 17 May 2021 / Published online: 15 June 2021

(c) The Author(s) 2021. This article is published with open access

\begin{abstract}
Gestational diabetes mellitus (GDM) is a common disorder of pregnancy with short- and long-term consequences for mother and baby. Pre-eclampsia is of major concern to obstetricians due to its sudden onset and increased morbidity and mortality for mother and baby. The incidence of these conditions continues to increase due to widespread maternal obesity. Maternal obesity is a risk factor for GDM and pre-eclampsia, yet our understanding of the role of adipose tissue and adipocyte biology in their aetiology is very limited. In this article, available data on adipose tissue and adipocyte function in healthy and obese pregnancy and how these are altered in GDM and pre-eclampsia are reviewed. Using our understanding of adipose tissue and adipocyte biology in non-pregnant populations, a role for underlying adipocyte dysfunction in the pathological pathways of these conditions is discussed.
\end{abstract}

\section{Introduction}

Maternal obesity (body mass index $[\mathrm{BMI}]>30 \mathrm{~kg} / \mathrm{m}^{2}$ ) is a major public health concern which can predispose to higher rates of adverse pregnancy outcomes, particularly the metabolic disorders of gestational diabetes mellitus (GDM) and pre-eclampsia $[1,2]$. GDM is defined as glucose intolerance of varying severity with first recognition during pregnancy and is characterised by $\beta$-cell dysfunction and exaggerated insulin resistance. Seventeen percent of live births globally are affected by hyperglycaemia and $85 \%$ of these have GDM [3]. GDM is associated with an increase in pregnancy complications including antenatal disease, prematurity, complicated delivery, postnatal complications, stillbirths, macrosomia, small for gestational age babies, congenital anomalies and neonatal mortality and morbidity. Pre-eclampsia, a multi-system disorder particular to human pregnancy is also a leading cause of maternal and neonatal

Supplementary information The online version contains supplementary material available at https://doi.org/10.1038/s41430021-00948-9.

Dilys J. Freeman

Dilys.Freeman@glasgow.ac.uk

1 Institute of Cardiovascular and Medical Sciences, University of Glasgow, Glasgow, UK morbidity and mortality. It is characterised by widespread endothelial dysfunction, resulting in hypertension due to vasoconstriction, proteinuria attributable to glomerular damage and oedema secondary to increased vascular permeability. Pre-eclampsia is a complex disease encompassing different phenotypic presentations (early/late onset, obesity-related or not, severe/mild) which may or may not share common aetiologies. The incidence of pre-eclampsia is $2-8 \%$ and $1.7 \%$ of pregnancies complicated by preeclampsia resulted in neonatal death, $4.6 \%$ in major neonatal morbidity and $67 \%$ in admission to a neonatal special care unit [4]. Women with pre-eclampsia have increased insulin resistance leading to a metabolic adaptation to pregnancy not dissimilar to metabolic syndrome [5]. This may explain at least in part the link with BMI, however, insulin resistance also predicts pre-eclampsia independent of maternal BMI [6].

As rates of maternal obesity have been increasing so has the incidence of these two diseases of pregnancy. The link with maternal obesity may be related to the adverse effects of adiposity on maternal metabolism and inflammation. However, meta-analysis of lifestyle interventions to reduce gestational weight gain (GWG) has shown that a reduction in GWG does not reduce adverse pregnancy outcomes including pre-eclampsia and GDM [7]. This suggests that the link between maternal obesity and risk of pre-eclampsia and GDM may not be straightforward. The aim of this review is to use our knowledge of adipose tissue function 
and how it contributes to metabolic disease in non-pregnant individuals to understand the pathological pathways which may underlie adiposity-related adverse pregnancy outcomes.

\section{Methodology}

A systemised review of adipose tissue and adipocytes in GDM and pre-eclampsia was carried out. A search of published literature using PubMed and MEDLINE was conducted independently by two investigators using the keywords: "adipose" OR "adipocyte" OR "subcutaneous OR visceral OR omental OR ectopic NEAR fat" OR "lipolysis" combined with "pregnancy" OR "gestation" OR "maternal", "gestational diabetes mellitus" OR "preeclampsia" OR "hypertens* NEAR pregnancy" using the operator AND. Duplicates were removed and all 2296 articles were screened by title and abstract for inclusion. Articles were excluded if: BMI was the only assessment of body fatness; there was a lack of healthy control group; an abstract could not be found or was a conference proceeding; only fetal outcomes were measured or the article was published in a language other than English. The number of total publications assessed was 176 . This list was supplemented for the wider review with references that provided background information on non-pregnant adipose tissue function, healthy and obese adaptation to pregnancy and clinical features of healthy and complicated pregnancy. A maximum of 100 references could be cited in this article. Non-cited reference material is available as Supplementary References.

\section{Adipose tissue function in healthy non-pregnant individuals}

Adipose tissue is not a single, uniform organ but is organised and distributed throughout the body into distinct anatomical and functional depots which determine its role in energy homeostasis and its association with disease. Adipose tissues are divided into three subtypes: white, brown and beige. Whilst brown adipose tissue has an important role in thermogenesis and beige adipose tissue is of emerging interest as a site of fat oxidation, white adipose tissue (WAT) is the primary site of lipid storage and mobilisation in humans and is the focus of this review. WAT acts as a buffer against the toxic effects of excess circulating lipids by storing free fatty acids (FFA) in adipocytes and releasing them for use by peripheral tissues in times of relative energy depletion. Peripheral, subcutaneous adipose tissue (SAT) is the largest depot and is the primary storage site of fatty acids as triglyceride. SAT can be located in the upper and lower body; lower body SAT is more insulin sensitive and stores fatty acids securely, whereas upper body SAT is relatively insulin resistant and has a greater propensity to release fatty acids from storage. Central, visceral adipose tissue (VAT) is associated with the development of obesityrelated disorders, probably via the release of fatty acids directly into the portal circulation. The extent and site of lipid storage in response to energy excess is regulated by endocrine function, the rate of lipid utilisation and the expansion capacity of WAT.

Uptake of fatty acids is mediated via lipoprotein lipase (LPL) that is secreted by adipocytes and situated on the vascular endothelium of adipose tissue. LPL hydrolyses FFA from triglycerides contained in triglyceride-rich lipoproteins such as chylomicrons and Very low density lipoprotein (VLDL), allowing their uptake into adipocytes via fatty acid transporters in the adipocyte membrane. The release of FFA from adipose tissue is governed by lipolysis of triglyceride, regulated via a trio of enzymes in a stepwise manner: adipose triglyceride lipase, hormone sensitive lipase (HSL) and monoglyceride lipase. Insulin is a key hormone that inhibits adipocyte lipolysis and increases glucose uptake. Healthy adipose tissue displays metabolic flexibility, whereby lipolysis is carefully regulated by hormones, catecholamines and paracrine signals to facilitate physiological responses to changes in requirements for lipid storage versus mobilisation. FFA released from SAT are returned to the liver for oxidation or secretion in VLDL. Upper body SAT is estimated to be the source of $60 \%$ of circulating FFA, lower body SAT $15-20 \%$ and VAT 6-17\% [8]. While VAT displays lower or equivalent rates of lipolysis to SAT, it has greater responsiveness to lipolytic stimuli and reduced responsiveness to inhibition by insulin.

Adipokines and cytokines secreted by adipocytes, adipose-resident immune cells, endothelial cells and other cellular compartments of the adipose tissue can have a diverse range of autocrine and paracrine effects which act to regulate insulin sensitivity, inflammation, cardiovascular function, behaviour and cell growth. Adiponectin, one of the most abundant adipokines in circulation, is antiinflammatory, insulin sensitising and is inversely associated with increased adiposity. Leptin, the most wellcharacterised adipokine, correlates with fat mass and is increased post-prandially, regulating food intake and glucose and fat metabolism in healthy individuals. In contrast to adiponectin, leptin has pro-inflammatory actions and is associated with increased adiposity and insulin resistance. There are numerous other adipokines which are not the focus of this current review and are discussed elsewhere [9]. Obesity is a state of chronic low-grade inflammation and obesity-induced insulin resistance precedes macrophage accumulation and inflammation in adipose tissue [10]. Increased accumulation of immune cells and production of 
pro-inflammatory molecules is a key mechanism by which adipose tissue contributes to increasing insulin resistance and dyslipidaemia. Adipose tissue may convey signals to other tissues via the protein, lipid and microRNA content of extracellular vesicles produced and released by adipocytes or other cells within adipose tissue [11].

\section{Adipose tissue expandability, insulin resistance and cardio-metabolic disease}

BMI is a universally accepted measure of body fatness and biomarker of metabolic disease risk when used in conjunction with other risk factors and is routinely measured in clinical settings. However, because BMI does not measure either the quantity or quality of body fat or convey any information about its location (SAT or VAT), it is relatively indiscriminate in predicting cardio-metabolic risk in comparison to central obesity with high intra-abdominal VAT. BMI is thus a proxy marker of adiposity, which cannot distinguish individuals who store fat in SAT in a relatively benign way, from those who store fat in VAT, which is related to metabolic dysfunction and pathology. In addition, the site of fat storage is recognised to be influenced by ethnicity, age, smoking and diet, which strongly suggests that the efficacy of BMI as a risk discriminator will vary between different populations.

Adipose tissue is comprised of adipocytes and stromal cells including pre-adipocytes and immune cells, which support the proliferation and differentiation of preadipocytes to adipocytes and secrete a variety of cytokines and growth factors facilitating this. When individuals become obese, excess calories are stored as triglyceride within the adipocytes of WAT. If there is insufficient capacity in mature adipocytes, new adipocytes are formed from pre-adipocytes in order to increase storage capacity. The formation of adipocytes (adipogenesis) occurs in two phases. The first phase is commitment to differentiation and involves the production of committed white pre-adipocytes from mesenchymal stem cells. Terminal differentiation forms mature adipocytes containing a lipid droplet that occupies almost all the space within the cell. In some individuals there appears to be a limited ability to produce mature adipocytes from pre-adipocytes (hyperplastic adipocyte expansion) and instead excess fatty acids are stored in existing mature adipocytes leading to an increase in their size (hypertrophic expansion) [12, 13]. In obese women hyperplasia is predominantly observed in SAT expansion, whereas hypertrophy is observed in both SAT and VAT adipocytes [14]. Larger adipocytes are dysfunctional and are demonstrably insulin resistant resulting in increased lipolysis due to resistance to the anti-lipolytic effects of insulin $[15,16]$. Healthy individuals with a family history of type 2 diabetes mellitus (T2DM) show higher SAT diameter compared to BMI-matched controls and SAT size is independently correlated with insulin resistance in a variety of populations [17]. It is not clear to what degree adipocyte differentiation is limited by insulin resistance or whether insulin resistance results from impaired adipocyte differentiation or both. Failure of angiogenesis and the resulting inadequate blood supply to hypertrophic adipocytes leads to necrosis, macrophage infiltration into adipose tissue, inflammation and dysregulated adipokine release. Increased fibrosis is also associated with obese adipose tissue, further contributing to limited adipocyte expandability, tissue hypoxia and a pro-inflammatory environment.

Once SAT capacity is exceeded, lipids begin to accumulate in visceral and finally ectopic tissues [13]. "Spillover" of fatty acids unable to be retained in subcutaneous adipocytes, either due to an insufficient number of mature adipocytes or due to hypertrophic adipocytes becoming insulin resistant, leads to an increase in the visceral fat compartment and simultaneously a flux of fatty acids into ectopic sites, stored as intracellular lipid droplets in tissues such as liver, heart and pancreas. It is not the absolute amount of fat mass per se that determines adiposity-related risk, but it is the amount of VAT and ectopic fat accrued which is metabolically unfavourable [18]. The formation of ectopic fat is closely linked to the development of insulin resistance and T2DM. Thus, individuals with limited adipocyte expandability, such as South Asians, are at increased risk of T2DM [19]. In mouse models, inhibition of adipocyte lipolysis reduces both insulin resistance and ectopic fat accumulation [20]. Thus, adipocyte dysfunction plays an integral part in the pathological pathway of T2DM.

\section{Maternal metabolic adaption to pregnancy and gestational fat storage (Fig. 1A)}

Adipose tissue expansion is an adaptive response to healthy human pregnancy. Maternal body composition and metabolism undergo dramatic changes in order to provide the developing fetus with a continuous supply of nutrients and prepare the mother for lactation. The initial phase of gestation is anabolic when maternal fat stores increase to a peak towards the end of the second trimester due to adipocyte hyperplasia and increased adipose tissue lipogenesis. Metabolism switches to a catabolic state around midgestation, characterised by increased adipose tissue fatty acid turnover and increased levels of lipolysis. Gluteal SAT adipocytes increased in size and number by late pregnancy in healthy non-obese women and adipose tissue showed increased expression of genes involved in tissue remodeling, angiogenesis and inflammation [21]. Increased rates of lipolysis are driven by maternal insulin resistance in response to gestational hormones, with adipocytes demonstrating reduced insulin suppression of lipolysis in late 

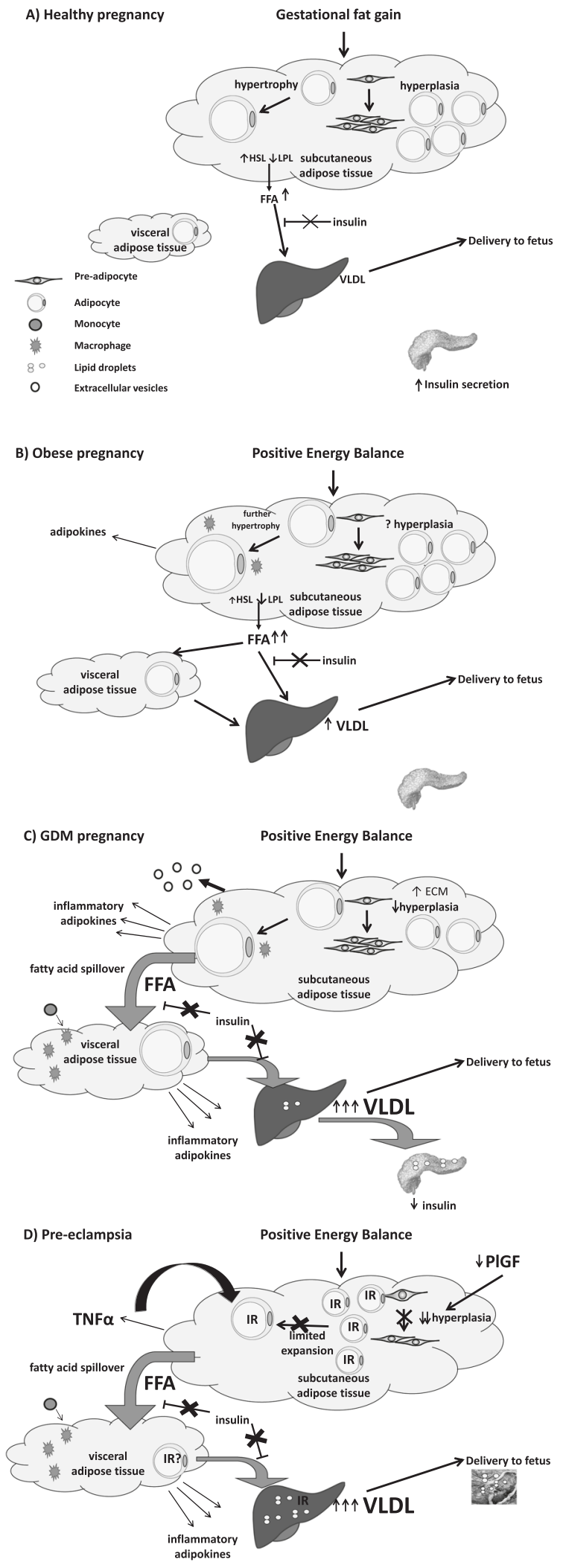

pregnancy compared to early pregnancy. Animal studies suggest there is a shift in the HSL to LPL expression ratio to favour lipolysis [22]. Lipolysis of maternal adipose stores
Fig. 1 Adipocyte function in healthy, obese, GDM and preeclampsia pregnancy. A In healthy pregnancy gestational fat storage is accommodated by adipocyte hypertrophy. The physiologically healthy level of insulin resistance permits controlled adipocyte lipolysis in order to supply triglycerides to the fetus via placental uptake of fatty acids from maternal VLDL. B Obese women already exhibit SAT and VAT adipocyte hypertrophy prior to pregnancy. During pregnancy they develop a greater degree of insulin resistance than lean women which reduces the ability of insulin to downregulate adipocyte lipolysis. This results in increased FFA flux to the liver and increased liver VLDL production. C In women who develop GDM, it is hypothesised that there is reduced hyperplasia and SAT hypertrophy resulting in fatty acid spillover. These fatty acids can cascade to ectopic sites including VAT, the liver and the pancreas and may lead to pancreatic dysfunction $\beta$-cell failure and the development of GDM. D In women who develop pre-eclampsia, it is hypothesised that there is an innate maternal insulin resistance manifest in both SAT and VAT. This insulin resistance reduces adipocyte differentiation, reducing the number of mature adipocytes and thereby reducing the capacity of SAT to store fat. Fatty acid spillover occurs leading to hypertriglyceridaemia and deposition of ectopic fat in the liver and placenta contributing to further maternal insulin resistance and placental dysfunction. FFA free fatty acid, HSL hormone-sensitive lipase, LPL lipoprotein lipase, SAT subcutaneous adipose tissue, VAT visceral adipose tissue, VLDL very low density lipoprotein.

accumulated in early pregnancy, coupled with reduced glucose uptake into maternal tissues, induced by maternal insulin resistance, ensures maximum nutrient availability for the developing fetus. In parallel with the accumulation of maternal adipose tissue, levels of circulating leptin in pregnancy increase to a maximum between 20 and 30 weeks of gestation. Low plasma levels of adiponectin are evident in pregnancy and appear to be linked to decreased insulin sensitivity of glucose disposal rather than lipid metabolism.

In pregnancy there is a shift in fat distribution from the lower body towards the upper abdominal region. The increase in abdominal fat in pregnancy has been found to be attributable to accumulation of VAT rather than SAT and there is an increase in VAT accumulation throughout gestation even in healthy pregnancy. Regional differences in SAT function were observed in pregnancy, with LPL activity in adipocytes from the femoral region, but not the abdominal region, increasing in pregnant women [23, 24]. Adiponectin mRNA expression does not differ between SAT and VAT in pregnant women [25].

\section{Maternal obesity and adipose tissue function (Fig. 1B)}

Despite lean and obese women accumulating similar amounts of gestational fat, the distribution of adipose tissue storage varies dependent on pre-pregnancy BMI. Skinfold thickness measurements show that lean pregnant women gain significantly more fat in lower body compartments, whereas obese pregnant women gain more in upper body 
compartments [26]. Further, lean pregnant women gain weight at a quicker rate than overweight and obese pregnant women, and increased VAT accumulation is found in those who are overweight and obese [27]. VAT thickness in early pregnancy correlates better with metabolic risk factors than maternal BMI. VAT thickness in pregnancy has also been found to correlate with levels of C-reactive protein and glycated haemoglobin [28, 29]. An impaired immune response in pregnant women, indicated by decreased expression of $\mathrm{CD}^{+} \mathrm{T}$ cell cytokines, correlated with abdominal VAT but not SAT [30].

Consistent with non-pregnant women, obesity in pregnancy is characterised by insulin resistance, dyslipidaemia and low-grade chronic inflammation [31, 32]. SAT and VAT expression of genes involved in adipocyte fatty acid uptake were generally decreased in obese compared to lean women in the third trimester of pregnancy [33], while others such as fatty acid synthase were unchanged [33]. SAT and VAT expression of genes involved in adipocyte lipolysis and of transcription factors regulating fatty acid metabolism (LXR $\alpha, \operatorname{PPAR} \alpha, \operatorname{PPAR} \delta, \mathrm{RXR} \alpha, \mathrm{SREBP} 1 \mathrm{c})$ and adipogenesis (PPAR $\gamma$ ) were lower in obese compared to lean women [33]. Obese pregnant women were less able to adapt substrate metabolism in accordance with fuel availability, which was associated with increased postprandial inflammation and insulin resistance [31, 34].

The higher levels of inflammation in obese compared to lean women suggest that adipokines may play a role in the pathophysiology of obesity-related pregnancy, possibly via endothelial dysfunction [32]. There were higher levels of leptin in maternal obesity compared to lean pregnant women which contributed to leptin resistance [35]. Circulating levels of adiponectin were significantly lower in obese compared to lean pregnant women [31], however this was not associated with increased levels of proinflammatory cytokines [32, 36]. Hypoadiponectinemia in late obese pregnancy was attributable to reduced expression and methylation of the adiponectin gene [37]. When VAT tissue explants were studied ex vivo, VAT from obese women tended to secrete higher levels of pro-inflammatory mediators and upon exposure to inflammatory stimuli the tissue explants reduced the expression of genes involved in fatty acid uptake and lipolysis [33].

\section{Adipocyte function in lean and obese pregnancy}

Adipocytes in abdominal SAT at gestational weeks 8-12 were non-significantly larger in obese pregnant women (mean diameter $91 \mu \mathrm{m})$ than lean pregnant women $(79 \mu \mathrm{m})$ [38]. Obese women also had twice as many SAT adipocytes as lean women in the first trimester [38]. Between the first and third trimester, lean women significantly increased SAT adipocyte diameter (to $87 \mu \mathrm{m}$ ) but not adipocyte number, whereas obese women displayed no change in diameter ( $87 \mu \mathrm{m}$ in the third trimester) or number over pregnancy [38]. There was evidence of a heterogeneous response where, when those who had gestational weight loss were excluded, obese women showed an increase in adipocyte number [38]. Third trimester SAT [39, 40] and VAT [41] adipocyte hypertrophy has also been reported in obese compared to lean third trimester pregnant women. Others have reported that obese women had fewer adipocytes and increased evidence of necrosis and apoptosis suggesting a higher adipocyte turnover and greater adipose tissue remodelling compared to lean pregnant women [39]. Analysis of the SAT and VAT transcriptome showed that a large number of genes in SAT had a gestational response compared to very few in VAT [42]. There was a trend towards lower SAT PPAR $\gamma$ expression in obese pregnant women compared to non-pregnant BMI-matched controls [43]. These data suggest that lean women undergo adipocyte hypertrophy in response to pregnancy, whereas obese women may already have adipocytes that have undergone hypertrophy prior to pregnancy. In obese women, gestational fat gain appears to be accommodated by an increase in cell number or increased adipose tissue remodelling. Some have observed no difference in SAT macrophage content between lean and obese women, and no gestational change in either group [38]. Others have identified higher SAT macrophage number [39] and a changed VAT macrophage population composition in maternal obesity [41].

Insulin binding to SAT adipocytes was reduced by more than $50 \%$ in the third trimester of pregnancy compared to non-pregnant controls [40, 44, 45] and was further decreased in obese pregnant women [40]. SAT adipocyte lipolytic activity increased over gestation in both lean and obese women despite obese women having a somewhat higher lipolytic activity in early pregnancy [38]. Insulin suppression of adipocyte lipolysis was decreased in obese compared to lean pregnant women [40]. Similarly, while there was no difference in adipocyte basal glucose uptake between non-pregnant and pregnant women, there was impaired insulin-stimulated glucose transport [44, 45] and evidence of defective post-receptor insulin signalling in pregnancy [44], although others disagree [45, 46]. Lower expression of GLUT1 and GLUT4 [47] and higher expression of IRS-2 were observed in adipocytes from obese pregnancies compared to obese non-pregnant adipose tissue [43] and in adipocytes from obese compared to nonobese pregnancies although this latter observation was not confirmed by protein expression [47]. There was also a trend towards lower basal and insulin-stimulated lipogenesis in pregnant women compared to non-pregnant [44]. IL6 and TNF $\alpha$ release was not different between lean and obese groups and was unchanged over gestation, whereas adipocyte adiponectin release significantly declined in lean, 


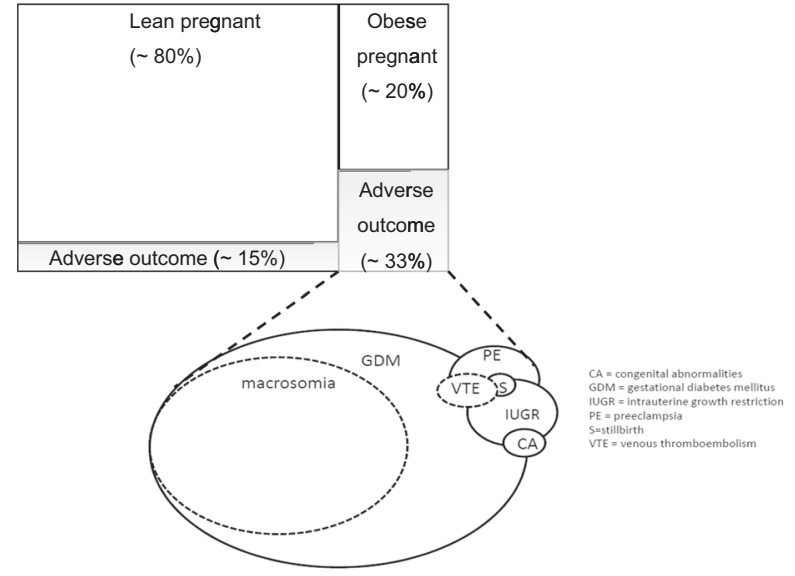

Fig. 2 Body mass index is a poor discriminator of obesity-related adverse pregnancy outcome. Approximately $20 \%$ of all pregnancies are in mothers who are obese at the time of antenatal booking (around 11 weeks' gestation) and undergo expensive, intensive antenatal monitoring. However, this percentage varies widely across different countries. Approximately one-third of obese mothers have an adverse pregnancy outcome. Obese mothers appear to be twice as likely to suffer an adverse pregnancy outcome than non-obese mothers, yet there is little information on how this varies between populations. There are a variety of obesity-related adverse outcomes of varying prevalence (represented by circle size). The underlying cause of adverse outcomes in obese mothers is often linked to metabolic dysregulation.

but not obese, women. Adipocyte lipolysis was associated with insulin resistance assessed by Homeostasis Model Assessment (HOMA), in the first trimester and the proportion of large adipocytes correlated with insulin resistance in the third trimester [38].

\section{Adiposity and risk of metabolic disorders of pregnancy}

Pre-pregnancy BMI and early GWG are potentially modifiable risk factors for gestational hypertensive disorders and GDM [48-50]. Although BMI is a low-cost screening tool, the limitations of its effectiveness in discriminating between high- and low-risk pregnancy have not been formally tested. Importantly, only $\sim 30 \%$ of obese pregnant women have an adverse pregnancy outcome [51]. Thus, 70 out of every 100 women identified as high risk undergo expensive, intensive antenatal monitoring unnecessarily (Fig. 2). Consistently GDM and PE populations can be reliably distinguished by measures of central fatness (SAT, VAT or total abdominal adipose tissue thickness) using ultrasonography and bioelectrical impedance. VAT thickness [52] and adiponectin, a metabolic biomarker associated with VAT [53], as well as waist circumference [54] strongly predict GDM. Similarly, prospective cohort studies for pre-eclampsia indicate measures of central/visceral obesity, i.e. waist circumference [55] and VAT thickness [56] are predictive. Thus far, large-scale multi-centre studies assessing the predictive power of measures of adipose tissue thickness relative to BMI are lacking and there is a lack of consensus on appropriate risk-defining cut-offs which may be influenced by ethnicity [19]. Recent studies also support SAT thickness as a predictor of GDM [57] although this may be acting as a proxy marker for visceral adiposity.

\section{Adipose tissue and adipocyte function in GDM (Fig. 1C)}

Women with GDM had larger VAT adipocytes than normal glucose tolerant (NGT) controls and adipocyte size correlated with plasma glucose levels [58]. SAT expression of PPAR $\gamma$ was reduced in GDM compared to NGT controls $[33,43,59]$ but others have found no differences in SAT or VAT PPAR $\gamma$ mRNA expression between GDM and NGT. Third trimester SAT and VAT expression of genes involved in adipocyte fatty acid uptake were decreased in GDM women compared to NGT women of similar BMI [33]. In addition, SAT and VAT expression of genes involved in triglyceride synthesis, fatty acid synthesis and triglyceride lipolysis were decreased in GDM pregnancies compared to NGT controls [33]. Others found alterations in expression of VAT fatty acid binding and storage proteins, such as perilipin 1, consistent with increased lipolysis [60]. Expression of transcription factors regulating fatty acid metabolism were lower in GDM women compared to NGT controls in SAT only [33].

Insulin receptor expression was found to be lower in both SAT and VAT from women with GDM compared to BMImatched controls [61]. In comparative studies of non-obese and obese insulin-controlled GDM with BMI-matched controls, there was evidence for disruption in insulin receptor-signalling transduction pathway in SAT of GDM. Others have shown that defects in insulin-signalling pathways resided in VAT but not SAT. Neither SAT nor VAT leptin expression was different between GDM and BMImatched NGT controls [62]. Many mediators have been proposed to induce insulin resistance in adipocytes in GDM. Plasma levels of an inhibitor of LPL, angiopoietin 4 (ANGPTL4), are decreased in GDM pregnancy [63]. In a mouse adipocyte cell model (3T3-L1), downregulation of ANGPTL4 expression inhibited adipocyte glucose uptake and insulin signalling and increased expression of proinflammatory cytokines [63]. VAT adipocyte plasma membrane-associated protein (APMAP) was found to be downregulated in GDM [64]. In the 3T3-L1 model, inhibition of APMAP expression resulted in impaired insulin signalling and activated NFKB-mediated inflammatory signalling [64]. A higher number of extracellular vesicles of different proteomic composition were produced by VAT explants from GDM compared to NGT women [65]. The 
extracellular vesicles from the GDM explants increased the expression of genes involved in glucose metabolism in placental cells [65].

In a cohort matched for BMI, VAT, but not SAT, TNF $\alpha$ mRNA expression was higher in GDM compared to controls, whereas IL-6 expression was unchanged in both tissues [66]. Leptin secretion from SAT explants was higher in GDM compared to NGT controls in both insulin-controlled and diet-controlled GDM [67] but unaffected by exposure to a variety of cytokines and hormones. SAT adiponectin expression was lower in VAT in GDM compared to BMImatched controls [66]. Proteomic analyses showed in adipose tissue from GDM women that there was increased expression of inflammatory proteins and differential expression of proteins involved in mitochondrial dysfunction, sirtuin signalling and oxidative phosphorylation compared to BMI-matched NGT controls [60]. VAT, but not SAT, from women with GDM had higher macrophage infiltration compared to NGT controls and the degree of infiltration correlated with systemic insulin resistance, however these groups were not BMI-matched [68]. VAT tissue explants from GDM compared to NGT secreted higher levels of leptin but not IL-1 $\beta$, or TNF $\alpha$ and others have found increased VAT leptin expression in GDM [69]. Expression of genes that co-ordinate pro- and antiinflammatory pathways have been found to be altered in VAT from GDM [70]. Apart from a higher IL-8 expression in VAT, there was no difference in SAT and VAT mRNA expression of pro-inflammatory IL-6, IL-6 receptor and suppressor of cytokine signalling proteins 1 and 3 between GDM and BMI-matched NGT controls [71]. VAT from women with GDM showed higher expression and secretion of angiogenic proteins such as fms-like tyrosine kinase-1 (sflt-1), fibroblast growth factor (FGF2) and endoglin than BMI-matched controls [72]. Proteomics also revealed a higher expression of proteins involved in extracellular matrix in GDM VAT, suggesting a less flexible tissue which may limit expansion [60].

\section{Adipose tissue and adipocyte function in pre- eclampsia (Fig. 1D)}

Published data on adipocyte function in pre-eclampsia is extremely limited. The size distribution of SAT and VAT adipocytes was altered in pre-eclampsia with more adipocytes in the lowest tertile of diameters compared to controls suggesting limited adipocyte differentiation [73]. Women with pre-eclampsia show systemic insulin resistance [74] and increased whole body lipolysis [75]. In pre-eclampsia, mature adipocytes were functionally insulin resistant as evidenced by a reduced suppression by insulin of $\beta$-adrenergic stimulated lipolysis [73]. Women with preeclampsia have higher plasma levels of triglycerides when compared to healthy BMI-matched controls [76] which is evident before clinical manifestation of pre-eclampsia [77] and suggests there may be increased rates of adipocyte lipolysis in women who go on to develop pre-eclampsia. Studies in placental growth factor (PIGF)-deficient mice suggest that reduced PIGF, as is observed in pre-eclampsia in humans, is associated with impaired adipose tissue development and vascularisation and the development of insulin resistance [78]. Both SAT and VAT adiponectin mRNA expression were unaltered between control and preeclampsia BMI-matched mothers [25].

In VAT, there was increased activated macrophage infiltration in pre-eclampsia and ex vivo adipocytes isolated from women with pre-eclampsia had higher inflammatory cytokine release in response to a pro-inflammatory stimulus [79]. Neutrophil infiltration was observed in the resistance vessels of SAT of women with pre-eclampsia [80]. Exposure of primary human adipocytes to human serum from women with pre-eclampsia increased mRNA expression of IL-6 and MCP-1 when compared to exposure to control serum [81]. In contrast, transcriptome profiling data from non-pregnant VAT exposed to pre-eclampsia sera suggested that these non-pregnant adipocytes are capable of mounting an anti-inflammatory response to the sera [82]. It was suggested that in vivo adipocyte inflammation might be provoked by advanced glycation end products or lipopolysaccharide [81]. Interestingly, despite preeclampsia being a disease of endothelial activation, there was no evidence of increased expression of proinflammatory endothelial activation markers in SAT from women with pre-eclampsia [83]. However, others have found increased expression of TNF $\alpha$ and ICAM- 1 in SAT from women with pre-eclampsia compared to controls [84]. Increased VAT adipocyte expression of TNF $\alpha$ in preeclampsia has been observed and VAT adipocyte TNF $\alpha$ release was inversely associated with VAT adipocyte insulin sensitivity [79].

\section{Evidence for ectopic fat accumulation in healthy and complicated pregnancy}

As described above, a failure of adipocyte expansion can lead to ectopic fat accumulation and development of insulin resistance and metabolic disease [18]. There is no evidence of ectopic fat accumulation in healthy pregnancy [85]. There is however evidence for this pathological pathway in pregnancies complicated by GDM and pre-eclampsia. Neither liver nor intra-myocellular fat was detected in women with GDM using magnetic resonance spectroscopy [86]. Plasma levels of gamma-glutaryl transferase, an indirect biochemical marker of liver fat, were predictive of GDM [87]. Recently, the presence of non-alcoholic fatty liver disease (NAFLD) during the initial period of gestation was 
identified as an independent risk factor for development of GDM [88]. In women with a history of GDM, liver fat rather than body composition was associated with insulin resistance [89], and these women develop NAFLD later in life [90]. There is evidence for ectopic fat accumulation in pre-eclampsia. Classically, the disease is characterised by atherosis of spiral arteries and the accumulation of lipids within glomerular endothelial cells [91]. This process is even more marked in the haemolysis, elevated liver enzymes and low platelet count syndrome and acute fatty liver of pregnancy, which are severe complications related to pre-eclampsia. Elevated plasma triglycerides were observed in pre-eclampsia [92], which is indicative of ectopic fat accumulation [93]. There is further indirect evidence of ectopic liver fat in pre-eclampsia as reduced long chain polyunsaturated fatty acid synthesis was observed in mothers with pre-eclampsia [94]. Placenta in pre-eclampsia had a higher total and neutral lipid (triglyceride and cholesteryl ester) content than in BMI-matched controls, which is preliminary evidence suggesting that ectopic lipid droplets may form in the placenta [95]. In addition, epicardial adipose thickness, an ectopic site of fat accumulation and a marker of visceral fat, was shown to predict both PE and GDM [96-98].

\section{Summary (Fig. 1)}

Impairment of adipocyte expansion is related to development of T2DM in non-pregnant populations and an understanding of this pathway sheds light on adipocyte function in pregnancy. GWG can easily be accommodated by adipocyte hypertrophy in healthy pregnancy. The relatively limited insulin resistance induced by pregnancy hormones in health leads to a regulated increase in lipolysis to supply nutrients to the fetus. In obese pregnancy, women commence pregnancy with a relative degree of SAT and VAT adipocyte hypertrophy and insulin resistance. In response to pregnancy hormones, obese women develop a higher than normal insulin resistance which reduces the ability of insulin to switch off lipolysis resulting in increased delivery of fatty acids to VAT and the liver leading to increased liver VLDL production and increased plasma triglyceride concentrations. There are limited data on adipocyte function in GDM and pre-eclampsia but that which is available suggests a role for adipocyte dysfunction in these diseases of pregnancy. In women who develop GDM, one might hypothesise that there is reduced hyperplasia and SAT hypertrophy resulting in fatty acid spillover. These fatty acids are directed to VAT which also experiences adipocyte hypertrophy and a reduced ability to retain fatty acids. Once the capacity of both depots is exceeded, then ectopic fat may begin to collect in the liver and pancreas leading to reduced pancreatic insulin secretion and tipping maternal metabolism into overt GDM. In women with pre-eclampsia, one might hypothesise that there is an innate maternal insulin resistance perhaps induced by changes in placental hormones secreted by a dysfunctional placenta. This insulin resistance impairs adipocyte differentiation, limiting the number of mature adipocytes and hence severely limiting the capacity of SAT to store gestationally acquired fat. Fatty acid spillover will occur, resulting in increased plasma lipids and ectopic fat accumulation in liver and placenta exacerbating further maternal insulin resistance and placental dysfunction. Clearly the evidence to support these hypotheses is limited and more data that will provide an understanding of the function of adipose tissue in GDM and pre-eclampsia is required.

\section{Future perspectives}

Metabolic complications of obese pregnancy may share a common metabolic origin with those found in non-pregnant obesity, through the development of insulin resistance. Although the concepts of benign and visceral obesity are only just beginning to be addressed in obstetric medicine, recognition of these obese phenotypes could have a major impact on the ability to identify high risk pregnancy. Currently, the ability to predict the onset of gestational disorders is limited, despite robust associations with BMI. A more detailed understanding of the pathological pathways related to adiposity may identify new risk factors to predict, and potential new treatments to prevent, GDM and preeclampsia.

Acknowledgements CT was funded by a British Heart Foundation 4 Year PhD Studentship FS/19/56/34893.

\section{Compliance with ethical standards}

Conflict of interest The authors declare no competing interests.

Publisher's note Springer Nature remains neutral with regard to jurisdictional claims in published maps and institutional affiliations.

Open Access This article is licensed under a Creative Commons Attribution 4.0 International License, which permits use, sharing, adaptation, distribution and reproduction in any medium or format, as long as you give appropriate credit to the original author(s) and the source, provide a link to the Creative Commons license, and indicate if changes were made. The images or other third party material in this article are included in the article's Creative Commons license, unless indicated otherwise in a credit line to the material. If material is not included in the article's Creative Commons license and your intended use is not permitted by statutory regulation or exceeds the permitted use, you will need to obtain permission directly from the copyright holder. To view a copy of this license, visit http://creativecommons. org/licenses/by/4.0/. 


\section{References}

1. O'Brien TE, Ray JG, Chan WS. Maternal body mass index and the risk of preeclampsia: a systematic overview. Epidemiology. 2003;14:368-74.

2. Torloni MR, Betran AP, Horta BL, Nakamura MU, Atallah AN, Moron AF, et al. Prepregnancy BMI and the risk of gestational diabetes: a systematic review of the literature with metaanalysis. Obes Rev. 2009;10:194-203. https://doi.org/10.1111/ j.1467-789X.2008.00541.x.

3. International Diabetes Federation. IDF Diabetes Atlas, 9th edn. Brussels, Belgium: International Diabetes Federation; 2019. Available at: https://www.diabetesatlas.org.

4. Vinnars MT, Nasiell J, Holmstrom G, Norman M, Westgren M, Papadogiannakis N. Association between placental pathology and neonatal outcome in preeclampsia: a large cohort study. Hypertens Pregnancy. 2014;33:145-58. https://doi.org/10.3109/10641955. 2013.842584.

5. Rodie VA, Freeman DJ, Sattar N, Greer IA. Pre-eclampsia and cardiovascular disease: metabolic syndrome of pregnancy. Atherosclerosis. 2004;175:189-202. https://doi.org/10.1016/j. atherosclerosis.2004.01.038

6. Hauth JC, Clifton RG, Roberts JM, Myatt L, Spong CY, Leveno $\mathrm{KJ}$, et al. Maternal insulin resistance and preeclampsia. Am J Obstet Gynecol. 2011;204:e321-6. https://doi.org/10.1016/j.ajog. 2011.02.024.

7. Rogozińska E, Marlin N, Jackson L, Rayanagoudar G, Ruifrok AE, Dodds J, et al. Effects of antenatal diet and physical activity on maternal and fetal outcomes: individual patient data meta-analysis and health economic evaluation. Health Technol Assess. 2017;21:1-158. https://doi.org/10.3310/hta21410.

8. Jensen MD. Role of body fat distribution and the metabolic complications of obesity. J Clin Endocrinol Metab. 2008;93: S57-63. https://doi.org/10.1210/jc.2008-1585.

9. Sethi JK, Vidal-Puig AJ. Thematic review series: adipocyte biology. Adipose tissue function and plasticity orchestrate nutritional adaptation. J lipid Res. 2007;48:1253-62. https://doi.org/10. 1194/jlr.R700005-JLR200.

10. Shimobayashi M, Albert V, Woelnerhanssen B, Frei IC, Weissenberger D, Meyer-Gerspach AC, et al. Insulin resistance causes inflammation in adipose tissue. $\mathrm{J}$ Clin Investig. 2018;128:1538-50. https://doi.org/10.1172/jci96139.

11. Gao X, Salomon C, Freeman DJ. Extracellular vesicles from adipose tissue - a potential role in obesity and type 2 diabetes? Front Endocrinol. 2017;8:202. https://doi.org/10.3389/fendo. 2017.00202.

12. Cuthbertson DJ, Steele T, Wilding JP, Halford JC, Harrold JA, Hamer $M$, et al. What have human experimental overfeeding studies taught us about adipose tissue expansion and susceptibility to obesity and metabolic complications? Int J Obes. 2017. https:// doi.org/10.1038/ijo.2017.4.

13. Gustafson B, Hedjazifar S, Gogg S, Hammarstedt A, Smith U. Insulin resistance and impaired adipogenesis. Trends Endocrinol Metab. 2015;26:193-200. https://doi.org/10.1016/j.tem.2015.01.006.

14. Drolet R, Richard C, Sniderman AD, Mailloux J, Fortier M, Huot $\mathrm{C}$, et al. Hypertrophy and hyperplasia of abdominal adipose tissues in women. Int J Obes. 2008;32:283-91. https://doi.org/10. 1038/sj.ijo.0803708.

15. Ibrahim MM. Subcutaneous and visceral adipose tissue: structural and functional differences. Obes Rev. 2010;11:11-8. https://doi. org/10.1111/j.1467-789X.2009.00623.x.

16. Laforest S, Labrecque J, Michaud A, Cianflone K, Tchernof A. Adipocyte size as a determinant of metabolic disease and adipose tissue dysfunction. Crit Rev Clin Lab Sci. 2015;52:301-13. https://doi.org/10.3109/10408363.2015.1041582.
17. McLaughlin T, Lamendola C, Coghlan N, Liu TC, Lerner K, Sherman A, et al. Subcutaneous adipose cell size and distribution: relationship to insulin resistance and body fat. Obesity. 2014;22:673-80. https://doi.org/10.1002/oby.20209.

18. Neeland IJ, Ross R, Despres JP, Matsuzawa Y, Yamashita S, Shai I, et al. Visceral and ectopic fat, atherosclerosis, and cardiometabolic disease: a position statement. Lancet Diabetes Endocrin. 2019. https://doi.org/10.1016/s2213-8587(19)30084-1.

19. Sattar N, Gill JM. Type 2 diabetes in migrant south Asians: mechanisms, mitigation, and management. Lancet Diabetes Endocrinol. 2015;3:1004-16. https://doi.org/10.1016/s2213-8587 (15)00326-5.

20. Schweiger M, Romauch M, Schreiber R, Grabner GF, Hutter S, Kotzbeck P, et al. Pharmacological inhibition of adipose triglyceride lipase corrects high-fat diet-induced insulin resistance and hepatosteatosis in mice. Nat Commun. 2017;8:14859. https://doi. org/10.1038/ncomms14859.

21. Resi V, Basu S, Haghiac M, Presley L, Minium J, Kaufman B, et al. Molecular inflammation and adipose tissue matrix remodeling precede physiological adaptations to pregnancy. Am J Physiol Endocrinol Metab. 2012;303:E832-40. https://doi.org/10. 1152/ajpendo.00002.2012.

22. Martin-Hidalgo A, Holm C, Belfrage P, Schotz MC, Herrera E. Lipoprotein lipase and hormone-sensitive lipase activity and mRNA in rat adipose tissue during pregnancy. Am J Physiol. 1994;266:E930-5.

23. Lindberg UB, Leibel RL, Silfverstolpe G, Hirsch J, Björntorp P, Rébuffé-Scrive M. Effects of early pregnancy on regional adipose tissue metabolism. Horm Metab Res. 1991;23:25-9. https://doi. org/10.1055/s-2007-1003603.

24. Rebuffé-Scrive M, Enk L, Crona N, Lönnroth P, Abrahamsson L, Smith U, et al. Fat cell metabolism in different regions in women. Effect of menstrual cycle, pregnancy, and lactation. J Clin Investig. 1985;75:1973-6. https://doi.org/10.1172/jci111914.

25. Liu Y, Zhu L, Pan Y, Sun L, Chen D, Li X. Adiponectin levels in circulation and breast milk and mRNA expression in adipose tissue of preeclampsia women. Hypertens Pregnancy. 2012;31:40-9. https://doi.org/10.3109/10641955.2010.525273.

26. Ehrenberg HM, Huston-Presley L, Catalano PM. The influence of obesity and gestational diabetes mellitus on accretion and the distribution of adipose tissue in pregnancy. Am J Obstet Gynecol. 2003;189:944-8.

27. Straughen JK, Trudeau S, Misra VK. Changes in adipose tissue distribution during pregnancy in overweight and obese compared with normal weight women. Nutr Diabetes. 2013;3:e84 https://doi. org/10.1038/nutd.2013.25.

28. Duran M, Kosus A, Kosus N, Turhan N. CRP, HbA1c, lipid, and biochemical parameters and their relation with maternal visceral adipose tissue and subcutaneous fat tissue thickness. Turkish $\mathrm{J}$ Med Sci. 2016;46:6-12. https://doi.org/10.3906/sag-1404-100.

29. Ozias MK, Li S, Hull HR, Brooks WM, Carlson SE. Relationship of circulating adipokines to body composition in pregnant women. Adipocyte. 2015;4:44-9. https://doi.org/10.4161/adip.29805.

30. Ozias MK, Li S, Hull HR, Brooks WM, Petroff MG, Carlson SE. Abdominal visceral adiposity influences CD4 $+\mathrm{T}$ cell cytokine production in pregnancy. Cytokine. 2015;71:405-8. https://doi. org/10.1016/j.cyto.2014.09.009.

31. Meyer BJ, Stewart FM, Brown EA, Cooney J, Nilsson S, Olivecrona $\mathrm{G}$, et al. Maternal obesity is associated with the formation of small dense LDL and hypoadiponectinemia in the third trimester. J Clin Endocrinol Metab. 2013;98:643-52. https://doi.org/10. 1210/jc.2012-3481.

32. Stewart FM, Freeman DJ, Ramsay JE, Greer IA, Caslake M, Ferrell WR. Longitudinal assessment of maternal endothelial function and markers of inflammation and placental function throughout pregnancy in lean and obese mothers. J Clin 
Endocrinol Metab. 2007;92:969-75. https://doi.org/10.1210/jc. 2006-2083.

33. Lappas M. Effect of pre-existing maternal obesity, gestational diabetes and adipokines on the expression of genes involved in lipid metabolism in adipose tissue. Metab Clin Exp. 2014;63:250-62. https://doi.org/10.1016/j.metabol.2013.10.001.

34. Tinius RA, Blankenship MM, Furgal KE, Cade WT, Pearson KJ, Rowland NS, et al. Metabolic flexibility is impaired in women who are pregnant and overweight/obese and related to insulin resistance and inflammation. Metab Clin Exp. 2020;104:154142. https://doi.org/10.1016/j.metabol.2020.154142.

35. Tessier DR, Ferraro ZM, Gruslin A. Role of leptin in pregnancy: consequences of maternal obesity. Placenta. 2013;34:205-11. https://doi.org/10.1016/j.placenta.2012.11.035.

36. Zembala-Szczerba M, Jaworowski A, Huras H, Babczyk D, Jach R. Low-grade metabolically-induced inflammation mediators interleukin-6, adiponectin, and $\mathrm{TNF}-\alpha$ serum levels in obese pregnant patients in the perinatal period. Med Sci Monit Basic Res. 2017;23:1-7. https://doi.org/10.12659/msmbr.902273.

37. Haghiac M, Basu S, Presley L, Serre D, Catalano PM, Mouzon S Hauguel-de. Patterns of adiponectin expression in term pregnancy: impact of obesity. J Clin Endocrinol Metab. 2014;99:3427-34. https://doi.org/10.1210/jc.2013-4074.

38. Svensson H, Wetterling L, Bosaeus M, Odén B, Odén A, Jennische $\mathrm{E}$, et al. Body fat mass and the proportion of very large adipocytes in pregnant women are associated with gestational insulin resistance. Int J Obes. 2016;40:646-53. https://doi.org/10. 1038/ijo.2015.232.

39. Haghiac M, Vora NL, Basu S, Johnson KL, Presley L, Bianchi DW, et al. Increased death of adipose cells, a path to release cellfree DNA into systemic circulation of obese women. Obesity. 2012;20:2213-9. https://doi.org/10.1038/oby.2012.138.

40. Pagano G, Cassader M, Massobrio M, Bozzo C, Trossarelli GF, Menato $\mathrm{G}$, et al. Insulin binding to human adipocytes during late pregnancy in healthy, obese and diabetic state. Horm Metab Res. 1980;12:177-81. https://doi.org/10.1055/s-2007-996237.

41. Bravo-Flores E, Mancilla-Herrera I, Espino YSS, Ortiz-Ramirez M, Flores-Rueda V, Ibargüengoitia-Ochoa F, et al. Macrophage populations in visceral adipose tissue from pregnant women: potential role of obesity in maternal inflammation. Int J Mol Scie. 2018;19. https://doi.org/10.3390/ijms19041074.

42. Mazaki-Tovi S, Vaisbuch E, Tarca AL, Kusanovic JP, Than NG, Chaiworapongsa $\mathrm{T}$, et al. Characterization of visceral and subcutaneous adipose tissue transcriptome and biological pathways in pregnant and non-pregnant women: evidence for pregnancyrelated regional-specific differences in adipose tissue. PLoS ONE. 2015;10:e0143779. https://doi.org/10.1371/journal.pone.0143779.

43. Catalano PM, Nizielski SE, Shao J, Preston L, Qiao L, Friedman JE. Downregulated IRS-1 and PPARgamma in obese women with gestational diabetes: relationship to FFA during pregnancy. Am J Physiol Endocrinol Metab. 2002;282:E522-33. https://doi.org/10. 1152/ajpendo.00124.2001.

44. Hjøllund E, Pedersen O, Espersen T, Klebe JG. Impaired insulin receptor binding and postbinding defects of adipocytes from normal and diabetic pregnant women. Diabetes. 1986;35:598-603. https://doi.org/10.2337/diab.35.5.598.

45. Ciaraldi TP, Kettel M, el-Roeiy A, Madar Z, Reichart D, Yen SS, et al. Mechanisms of cellular insulin resistance in human pregnancy. Am J Obstet Gynecol. 1994;170:635-41. https://doi.org/ 10.1016/s0002-9378(94)70241-1.

46. Bruce C, Bumby J, Mangnall D, Fraser RB. Evidence that the insulin resistance of pregnancy may not involve a post-receptor defect in human adipocytes. Diabetes Res Clin Pr. 1992;16:75-84. https://doi.org/10.1016/0168-8227(92)90076-4.

47. Colomiere M, Permezel M, Lappas M. Diabetes and obesity during pregnancy alter insulin signalling and glucose transporter expression in maternal skeletal muscle and subcutaneous adipose tissue. J Mol Endocrinol. 2010;44:213-23. https://doi.org/10. 1677/jme-09-0091.

48. Gilmore LA, Klempel-Donchenko M, Redman LM. Pregnancy as a window to future health: excessive gestational weight gain and obesity. Semin Perinatol. 2015;39:296-303. https://doi.org/10. 1053/j.semperi.2015.05.009.

49. Sween LK, Althouse AD, Roberts JM. Early-pregnancy percent body fat in relation to preeclampsia risk in obese women. Am J Obstet Gynecol. 2015;212:84.e81-87. https://doi.org/10.1016/j. ajog.2014.07.055.

50. Wang Y, Qiu J, Zhou M, Wang Y, Du Y. Increasing maternal percentage body fat in early second trimester: a risk factor for preeclampsia. J Matern-Fetal Neonatal Med. 2015;28:293-6. https://doi.org/10.3109/14767058.2014.916265.

51. Chu SY, Bachman DJ, Callaghan WM, Whitlock EP, Dietz PM, Berg CJ, et al. Association between obesity during pregnancy and increased use of health care. N Engl J Med. 2008;358:1444-53. https://doi.org/10.1056/NEJMoa0706786.

52. Martin AM, Berger H, Nisenbaum R, Lausman AY, MacGarvie S, Crerar $\mathrm{C}$, et al. Abdominal visceral adiposity in the first trimester predicts glucose intolerance in later pregnancy. Diabetes Care. 2009;32:1308-10. https://doi.org/10.2337/dc09-0290.

53. Maitland RA, Seed PT, Briley AL, Homsy M, Thomas S, Pasupathy D, et al. Prediction of gestational diabetes in obese pregnant women from the UK Pregnancies Better Eating and Activity (UPBEAT) pilot trial. Diabet Med. 2014;31:963-70. https://doi. org/10.1111/dme.12482.

54. Bolognani CV, de Sousa Moreira Reis LB, de Souza SS, Dias A, Rudge MV, de Mattos Paranhos Calderon I. Waist circumference in predicting gestational diabetes mellitus. J Matern-Fetal Neonatal Med. 2014;27:943-8. https://doi.org/10.3109/14767058. 2013.847081.

55. Sattar N, Clark P, Holmes A, Lean ME, Walker I, Greer IA. Antenatal waist circumference and hypertension risk. Obstet Gynecol. 2001;97:268-71.

56. Ray JG, De Souza LR, Park AL, Connelly PW, Bujold E, Berger H. Preeclampsia and preterm birth associated with visceral adiposity in early pregnancy. J Obstet Gynaecol Can. 2017;39:78-81. https://doi.org/10.1016/j.jogc.2016.10.007.

57. Suresh A, Liu A, Poulton A, Quinton A, Amer Z, Mongelli M, et al. Comparison of maternal abdominal subcutaneous fat thickness and body mass index as markers for pregnancy outcomes: a stratified cohort study. Aust N Z J Obstet Gynaecol. 2012;52:420-6. https://doi.org/10.1111/j.1479-828X.2012.01471. $\mathrm{x}$.

58. Rojas-Rodriguez R, Lifshitz LM, Bellve KD, Min SY, Pires J, Leung $\mathrm{K}$, et al. Human adipose tissue expansion in pregnancy is impaired in gestational diabetes mellitus. Diabetologia. 2015;58:2106-14. https://doi.org/10.1007/s00125-015-3662-0.

59. Gao Y, She R, Sha W. Gestational diabetes mellitus is associated with decreased adipose and placenta peroxisome proliferatoractivator receptor $\gamma$ expression in a Chinese population. Oncotarget. 2017;8:113928-37. https://doi.org/10.18632/oncotarget. 23043.

60. Oliva K, Barker G, Rice GE, Bailey MJ, Lappas M. 2D-DIGE to identify proteins associated with gestational diabetes in omental adipose tissue. J Endocrinol. 2013;218:165-78. https://doi.org/10. 1530/joe-13-0010.

61. Ott R, Melchior K, Stupin JH, Ziska T, Schellong K, Henrich W, et al. Reduced insulin receptor expression and altered DNA methylation in fat tissues and blood of women with GDM and offspring. J Clin Endocrinol Metab. 2019;104:137-49. https://doi. org/10.1210/jc.2018-01659.

62. Tsiotra PC, Halvatsiotis P, Patsouras K, Maratou E, Salamalekis $\mathrm{G}$, Raptis SA, et al. Circulating adipokines and mRNA expression 
in adipose tissue and the placenta in women with gestational diabetes mellitus. Peptides. 2018;101:157-66. https://doi.org/10. 1016/j.peptides.2018.01.005.

63. Li M, Yang XJ, Zhang GY, Su DX, Lei L, Li R. ANGPTL4 participates in gestational diabetes mellitus via regulating Akt pathway. Eur Rev Med Pharm Sci. 2018;22:5056-62. https://doi. org/10.26355/eurrev_201808_15697.

64. Ma Y, Gao J, Yin J, Gu L, Liu X, Chen S, et al. Identification of a novel function of adipocyte plasma membrane-associated protein (APMAP) in gestational diabetes mellitus by proteomic analysis of omental adipose tissue. J Proteome Res. 2016;15:628-37. https://doi.org/10.1021/acs.jproteome.5b01030.

65. Jayabalan N, Lai A, Ormazabal V, Adam S, Guanzon D, Palma C, et al. Adipose tissue exosomal proteomic profile reveals a role on placenta glucose metabolism in gestational diabetes mellitus. J Clin Endocrinol Metab. 2019;104:1735-52. https://doi.org/10. 1210/jc.2018-01599.

66. Telejko B, Kalejta K, Kuzmicki M, Wawrusiewicz-Kurylonek N, Lipinska D, Pliszka J, et al. The association of bone turnover markers with pro- and anti-inflammatory adipokines in patients with gestational diabetes. Ann Agric Environ Med. 2015;22:307-12. https://doi.org/10.5604/12321966.1152085.

67. Lappas M, Yee K, Permezel M, Rice GE. Release and regulation of leptin, resistin and adiponectin from human placenta, fetal membranes, and maternal adipose tissue and skeletal muscle from normal and gestational diabetes mellitus-complicated pregnancies. J Endocrinol. 2005;186:457-65. https://doi.org/10.1677/joe.1. 06227.

68. Harlev A, Aricha-Tamir B, Shaco-Levy R, Tarnovscki T, Bashan $\mathrm{N}$, Rudich A, et al. Macrophage infiltration and stress-signaling in omental and subcutaneous adipose tissue in diabetic pregnancies. J Matern-Fetal Neonatal Med. 2014;27:1189-94. https://doi.org/ 10.3109/14767058.2013.853734.

69. Kleiblova P, Dostalova I, Bartlova M, Lacinova Z, Ticha I, Krejci $\mathrm{V}$, et al. Expression of adipokines and estrogen receptors in adipose tissue and placenta of patients with gestational diabetes mellitus. Mol Cell Endocrinol. 2010;314:150-6. https://doi.org/ 10.1016/j.mce.2009.08.002.

70. Santangelo C, Filardi T, Perrone G, Mariani M, Mari E, Scazzocchio B, et al. Cross-talk between fetal membranes and visceral adipose tissue involves HMGB1-RAGE and VIP-VPAC2 pathways in human gestational diabetes mellitus. Acta Diabetol. 2019;56:681-9. https://doi.org/10.1007/s00592-019-01304-x.

71. Kuzmicki M, Telejko B, Wawrusiewicz-Kurylonek N, Citko A, Lipinska D, Pliszka J, et al. The expression of suppressor of cytokine signaling 1 and 3 in fat and placental tissue from women with gestational diabetes. Gynecol Endocrinol. 2012;28:841-4. https://doi.org/10.3109/09513590.2012.683055.

72. Lappas M. Markers of endothelial cell dysfunction are increased in human omental adipose tissue from women with pre-existing maternal obesity and gestational diabetes. Metab Clin Exp. 2014;63:860-73. https://doi.org/10.1016/j.metabol.2014.03.007.

73. Huda SS, Forrest R, Paterson N, Jordan F, Sattar N, Freeman DJ. In preeclampsia, maternal third trimester subcutaneous adipocyte lipolysis is more resistant to suppression by insulin than in healthy pregnancy. Hypertension. 2014;63:1094-101. https://doi.org/10. 1161/hypertensionaha.113.01824.

74. Kaaja R. Insulin resistance syndrome in preeclampsia. Semin Reprod Endocrinol. 1998;16:41-6. https://doi.org/10.1055/s2007-1016251.

75. Endresen MJ, Lorentzen B, Henriksen T. Increased lipolytic activity and high ratio of free fatty acids to albumin in sera from women with preeclampsia leads to triglyceride accumulation in cultured endothelial cells. Am J Obstet Gynecol. 1992;167:440-7. https://doi.org/10.1016/s0002-9378(11)91426-4.
76. Potter JM, Nestel PJ. The hyperlipidemia of pregnancy in normal and complicated pregnancies. Am J Obstet Gynecol. 1979;133:165-70. https://doi.org/10.1016/0002-9378(79)90469-1.

77. Enquobahrie DA, Williams MA, Butler CL, Frederick IO, Miller RS, Luthy DA. Maternal plasma lipid concentrations in early pregnancy and risk of preeclampsia. Am $\mathrm{J}$ hypertension. 2004;17:574-81. https://doi.org/10.1016/j.amjhyper.2004.03.666.

78. Hemmeryckx B, van Bree R, Van Hoef B, Vercruysse L, Lijnen HR, Verhaeghe J. Adverse adipose phenotype and hyperinsulinemia in gravid mice deficient in placental growth factor. Endocrinology. 2008;149:2176-83. https://doi.org/10.1210/en. 2007-1272.

79. Huda SS, Jordan F, Bray J, Love G, Payne R, Sattar N, et al. Visceral adipose tissue activated macrophage content and inflammatory adipokine secretion is higher in pre-eclampsia than in healthy pregnancys. Clin Sci. 2017;131:1529-40. https://doi. org/10.1042/cs20160832.

80. Leik CE, Walsh SW. Neutrophils infiltrate resistance-sized vessels of subcutaneous fat in women with preeclampsia. Hypertension. 2004;44:72-7. https://doi.org/10.1161/01.Hyp.0000130483. 83154.37.

81. Akasaka J, Naruse K, Sado T, Uchiyama T, Makino M, Yamauchi A, et al. Involvement of receptor for advanced glycation endproducts in hypertensive disorders of pregnancy. Int J Mol Sci. 2019;20. https://doi.org/10.3390/ijms20215462.

82. Naruse K, Akasaka J, Shigemitsu A, Tsunemi T, Koike N, Yoshimoto $\mathrm{C}$, et al. Involvement of visceral adipose tissue in immunological modulation of inflammatory cascade in preeclampsia. Mediators Inflamm. 2015;2015:325932. https://doi. org/10.1155/2015/325932.

83. Donker RB, Molema G, Faas MM, Kallenberg CG, van Pampus MG, Timmer A, et al. Absence of in vivo generalized proinflammatory endothelial activation in severe, early-onset preeclampsia. J Soc Gynecol Investig. 2005;12:518-28. https://doi. org/10.1016/j.jsgi.2005.06.007.

84. Zhao J, Zheng DY, Yang JM, Wang M, Zhang XT, Sun L, et al. Maternal serum uric acid concentration is associated with the expression of tumour necrosis factor- $\alpha$ and intercellular adhesion molecule-1 in patients with preeclampsia. J Hum Hypertens. 2016;30:456-62. https://doi.org/10.1038/jhh.2015.110.

85. Vesco K, Leo MC, Francisco M, Baetscher E, Rooney W, Marshall NE, et al. Is gestational weight gain associated with change in ectopic lipid stores. Diabetes. 2018;67:1407-P. https://doi.org/ 10.2337/db18-1407-P.

86. Vesco K, Leo MC, Francisco M, Marshall NE, Rooney W, Baetscher E, et al. 1386-P: a comparison of ectopic fat stores and insulin sensitivity among women with and without gestational diabetes. Diabetes. 2019;68:1386-P. https://doi.org/10.2337/ db19-1386-P.

87. Tan PC, Mubarak S, Omar SZ. Gamma-glutamyltransferase level in pregnancy is an independent risk factor for gestational diabetes mellitus. J Obstet Gynaecol Res. 2008;34:512-7. https://doi.org/ 10.1111/j.1447-0756.2008.00815.x.

88. Lee SM, Kwak SH, Koo JN, Oh IH, Kwon JE, Kim BJ, et al. Nonalcoholic fatty liver disease in the first trimester and subsequent development of gestational diabetes mellitus. Diabetologia. 2019;62:238-48. https://doi.org/10.1007/s00125-018-4779-8.

89. Tiikkainen M, Tamminen M, Häkkinen AM, Bergholm R, Vehkavaara S, Halavaara J, et al. Liver-fat accumulation and insulin resistance in obese women with previous gestational diabetes. Obes Res. 2002;10:859-67. https://doi.org/10.1038/oby.2002. 118.

90. Forbes S, Taylor-Robinson SD, Patel N, Allan P, Walker BR, Johnston DG. Increased prevalence of non-alcoholic fatty liver disease in European women with a history of gestational diabetes. 
Diabetologia. 2011;54:641-7. https://doi.org/10.1007/s00125010-2009-0.

91. Sattar N, Greer I. Lipids and the pathogenesis of pre-eclampsia. Curr Obstet Gynaecol. 1999;9:190-5.

92. Sattar N, Bendomir A, Berry C, Shepherd J, Greer IA, Packard CJ. Lipoprotein subfraction concentrations in preeclampsia: pathogenic parallels to atherosclerosis. Obstet Gynecol. 1997;89:403-8. https://doi.org/10.1016/s0029-7844(96)00514-5.

93. Chan DC, Gan SK, Wong AT, Barrett PH, Watts GF. Association between skeletal muscle fat content and very-low-density lipoprotein-apolipoprotein B-100 transport in obesity: effect of weight loss. Diabetes, Obes Metab. 2014;16:994-1000. https:// doi.org/10.1111/dom.12311.

94. Mackay VA, Huda SS, Stewart FM, Tham K, McKenna LA, Martin I, et al. Preeclampsia is associated with compromised maternal synthesis of long-chain polyunsaturated fatty acids, leading to offspring deficiency. Hypertension. 2012;60:1078-85. https://doi.org/10.1161/hypertensionaha.112.197897.
95. Brown SH, Eather SR, Freeman DJ, Meyer BJ, Mitchell TW. A lipidomic analysis of placenta in preeclampsia: evidence for lipid storage. PLoS ONE. 2016;11:e0163972 https://doi.org/10.1371/ journal.pone.0163972.

96. Altin C, Yilmaz M, Ozsoy HM, Gezmis E, Balci S, Tekindal MA, et al. Assessment of epicardial fat and carotid intima media thickness in gestational hypertension. J Obstet Gynaecol Res. 2018;44:1072-9. https://doi.org/10.1111/jog.13631.

97. Cakmak HA, Dincgez Cakmak B, Abide Yayla C, Inci Coskun E, Erturk M, Keles I. Assessment of relationships between novel inflammatory markers and presence and severity of preeclampsia: epicardial fat thickness, pentraxin-3, and neutrophil-tolymphocyte ratio. Hypertens Pregnancy. 2017;36:233-9. https:// doi.org/10.1080/10641955.2017.1321016.

98. Liu J, Song G, Meng T, Zhao G. Epicardial adipose tissue thickness as a potential predictor of gestational diabetes mellitus: a prospective cohort study. BMC Cardiovasc Disord. 2020;20:184. https://doi.org/10.1186/s12872-020-01480-7. 